\title{
АНАЛИЗ ТРАНСПОРТНОЙ ИНФРАСТРУКТУРЫ АРКТИЧЕСКОЙ ЗОНЫ РФ *
}

\author{
(c) 2020 Гизатуллина О.М. \\ кандидат экономических наук, доцент Департамента бизнес- аналитики \\ Финансовый университет при Правительстве Российской Федерации, Россия, Москва \\ E-mail: OMGizatullina@fa.ru \\ (c) 2020 Соловейчик М.С. \\ студент Факультета логистики \\ Финансовый университет при Правительстве Российской Федерации, Россия, Москва
}

В соответствии с утвержденным Указом Президента Российской Федерации Основами государственной политики РФ в Арктике до 2035 года среди ключевых стратегических целей региона, помимо прочих, указаны: развитие АЗРФ как стратегической ресурсной базы, обеспечивающей ускорение экономического роста страны, а также поддержание соответствующей инфраструктуры и создание на основе Северного морского пути конкурентоспособной на мировом рынке национальной транспортно-логистической системы РФ [1]. Реализация указанных целей подразумевает широкую и всестороннюю оптимизацию транспортно-логистической инфраструктуры российской Арктики для обеспечения реализации оптимальных сценариев экономического развития региона и страны в целом.

Ключевые слова: логистические затраты, Арктическая зона РФ, Северный транспортный коридор, оптимизация.

Развитие Арктической зоны Российской Федерации, которая обеспечивает до четверти объема экспорта российских природных ресурсов, вносит весомый вклад в создание ВВП страны (10-15\%) (таблица 1), а также выступает в роли региона особого значения с точки зрения обеспечения национальной безопасности РФ, предполагает создание целостной системы как добывающих, так и обрабатывающих отраслей промышленности в регионе на основе инновационных подходов и передовых технологий [2]. Реализация масштабных арктических проектов призвана обеспечить ресурсно-инновационное развитие АЗРФ посредством освоения богатейших запасов нефти и природного газа, создания условий для их переработки и транспортировки, служащих стимулом для развития ведущих отраслей отечественной экономики [3].

Среди явных рисков реализации подобной стратегии следует отметить тот факт, что производственно-хозяйственная деятельность в регионах АЗРФ на сегодняшний день носит очаговый характер, а слабое развитие транспортнологистической инфраструктуры и каналов коммуникации между экономическими субъектами приводит к очевидному несоответствию страте- гической роли российской Арктики и ее экономического потенциала имеющимся на текущий момент возможностям для их широкой реализации. Таким образом, одним из наиболее обоснованных направлений развития АЗРФ становится реализация программы по созданию системы транспортных коридоров, охватывающих все опорные зоны российской Арктики, включая акватории, а также создание соответствующей береговой логистической инфраструктуры.

Система международных транспортных коридоров под юрисдикцией Российской Федерации будет способствовать реализации транзитного потенциала уникального региона и созданию экономических стимулов развития по целому ряду направлений. Во-первых, совершенствование транспортно-логистической инфраструктуры обеспечит сбалансированность реализации промышленного потенциала региона, связав месторождения природных ресурсов полярного Урала, нефтегазовые месторождения Ямала и Гыданского полуострова с промышленно развитыми районами Северного и Среднего Урала. Во-вторых, повышение транспортной доступности населенных пунктов и экономических субъектов российского Заполярья соз-

\footnotetext{
* Статья подготовлена по результатам исследований, выполненных за счет бюджетных средств по государственному заданию Финуниверситету
} 


\begin{tabular}{|c|c|c|c|c|c|c|c|c|c|c|}
\hline $\begin{array}{c}\text { Инвестиции в основной каптал, } \\
\text { млрд. руб. }\end{array}$ & $\stackrel{n}{\stackrel{2}{\Lambda}}$ & $\underset{f}{\stackrel{O}{E}}$ & $\stackrel{m}{\stackrel{m}{a}}$ & $\approx$ & $\begin{array}{l}\stackrel{0}{0} \\
\stackrel{0}{\sim}\end{array}$ & 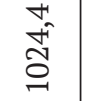 & के & 帨 & $\vec{n}$ & $\stackrel{F}{F}$ \\
\hline $\begin{array}{c}\text { Сальдированный финансовй } \\
\text { результат в экономике, млн. руб. }\end{array}$ & 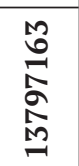 & 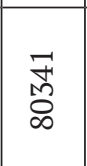 & 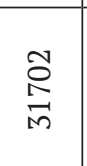 & 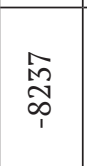 & $\stackrel{\substack{\infty \\
\stackrel{D}{\Xi}}}{\exists}$ & $\begin{array}{l}\text { Nิ } \\
\text { N } \\
\text { గn }\end{array}$ & $\begin{array}{l}\stackrel{\circ}{\triangle} \\
\text { तิ } \\
\text { in }\end{array}$ & 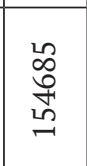 & $\stackrel{\infty}{\stackrel{\infty}{E}}$ & $\begin{array}{l}\infty \\
\infty \\
\infty \\
\infty \\
1\end{array}$ \\
\hline $\begin{array}{c}\text { Продукция сельского хозяйства, } \\
\text { млн. руб. }\end{array}$ & $\begin{array}{l}\stackrel{0}{n} \\
\stackrel{2}{=} \\
\text { in }\end{array}$ & $\underset{\infty}{\stackrel{M}{\infty}}$ & $\stackrel{\bumpeq}{\circ}$ & 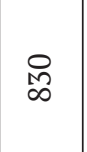 & 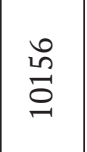 & 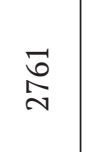 & 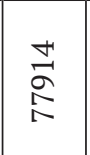 & 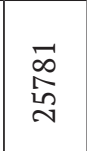 & $\stackrel{M}{M}$ & $\stackrel{\infty}{\&}$ \\
\hline $\begin{array}{c}\text { Водоснабжение, водоотведение, } \\
\text { ликвидация загрязнений, млн. } \\
\text { руб. }\end{array}$ & 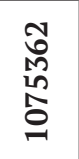 & 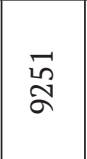 & นू & 능 & $\begin{array}{l}\vec{M} \\
\text { ભુ }\end{array}$ & 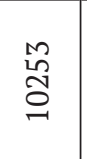 & $\begin{array}{l}m \\
\infty \\
\stackrel{m}{N}\end{array}$ & 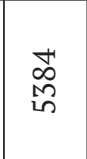 & $\vec{F}$ & $\frac{\infty}{\vec{\gamma}}$ \\
\hline $\begin{array}{c}\text { Обеспечение электрической энер- } \\
\text { гией, газом, паром, кондициони- } \\
\text { рование воздуха, млн. руб. }\end{array}$ & 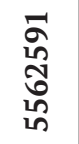 & $\begin{array}{l}\text { হ } \\
\text { হ } \\
\text { in }\end{array}$ & $\begin{array}{l}n \\
\infty \\
\infty \\
\infty \\
\infty\end{array}$ & $\begin{array}{l}\text { Mo } \\
\stackrel{0}{0}\end{array}$ & 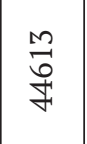 & 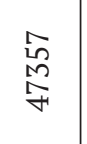 & 㣽 & 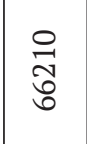 & $\stackrel{\text { Ln }}{\infty}$ & 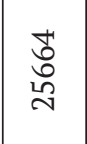 \\
\hline $\begin{array}{c}\text { Обрабатывающие производства, } \\
\text { млн. руб. }\end{array}$ & $\begin{array}{l}10 \\
\infty \\
\infty \\
\vdots \\
\vdots \\
\stackrel{y}{+}\end{array}$ & 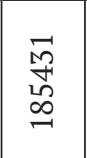 & 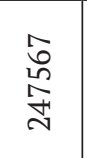 & 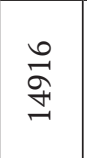 & $\begin{array}{l}\vec{\circ} \\
\text { m } \\
\text { a }\end{array}$ & 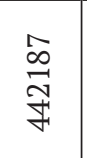 & 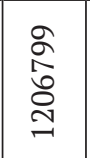 & 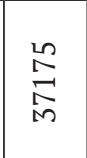 & 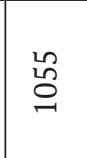 & $\begin{array}{l}0 \\
\underset{0}{0} \\
\stackrel{1}{-1}\end{array}$ \\
\hline $\begin{array}{c}\text { Добыча полезных ископаемых, } \\
\text { млн. руб. }\end{array}$ & $\begin{array}{l}\infty \\
\infty \\
\infty \\
\infty \\
\infty \\
0 \\
1\end{array}$ & $\begin{array}{l}\infty \\
\text { ஸू } \\
\text { Һ }\end{array}$ & 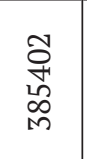 & $\begin{array}{l}\stackrel{M}{M} \\
\text { Nิ } \\
\text { M }\end{array}$ & $\begin{array}{l}\text { M } \\
\stackrel{1}{M} \\
\stackrel{\wp}{+}\end{array}$ & $\begin{array}{l}\stackrel{8}{\Omega} \\
\stackrel{2}{\circ} \\
\stackrel{+}{+}\end{array}$ & 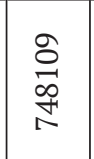 & \begin{tabular}{l}
$\infty$ \\
$\infty$ \\
$m$ \\
\multirow{M}{\infty}{} \\
$\infty$
\end{tabular} & 点 & $\begin{array}{l}\mathscr{L} \\
\stackrel{N}{M} \\
\cdots \\
\infty\end{array}$ \\
\hline $\begin{array}{c}\text { Основные фонды в экономике } \\
\text { по полной учетной стоимости } \\
\text { (01.01.2018), млрд. руб. }\end{array}$ & 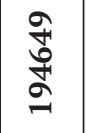 & $\stackrel{n}{n}_{\substack{n \\
N^{n}}}$ & $\begin{array}{l}\text { } \\
\stackrel{N}{M} \\
\stackrel{N}{N}\end{array}$ & $\stackrel{\infty}{\sharp}$ & Ma & $\begin{array}{l}\hat{\sigma} \\
\text { ồ } \\
\stackrel{-}{\sigma}\end{array}$ & 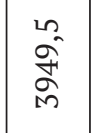 & $\underset{\sim}{\sharp}$ & $\begin{array}{l}m \\
\stackrel{m}{\Omega}\end{array}$ & 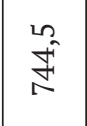 \\
\hline $\begin{array}{c}\text { Валовый региональный продукт, } \\
\text { млрд. руб. }\end{array}$ & $\begin{array}{l}\infty \\
\text { Lิ } \\
\text { సे }\end{array}$ & $\underset{f}{\infty}$ & $\underset{\substack{0 \\
\stackrel{N}{L}}}{2}$ & 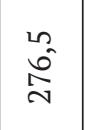 & $\stackrel{+}{i n}$ & $\begin{array}{l}\stackrel{+}{\vec{T}} \\
\stackrel{+}{*}\end{array}$ & $\begin{array}{l}\text { m } \\
\text { I } \\
\infty \\
\infty \\
-1\end{array}$ & $\begin{array}{l}0 \\
\sigma^{-} \\
\sigma\end{array}$ & $\hat{0}$ & ลิ \\
\hline $\begin{array}{c}\text { Среднемесячная заработная } \\
\text { плата, руб. }\end{array}$ & 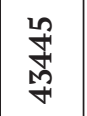 & $\begin{array}{l}\text { L } \\
\underset{\infty}{0} \\
\stackrel{0}{n}\end{array}$ & $\begin{array}{l}8 \\
\stackrel{1}{\circ} \\
\infty \\
+\infty\end{array}$ & 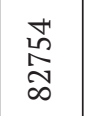 & $\stackrel{m}{\vec{H}}$ & 志 & 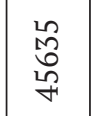 & $\begin{array}{l}\text { 덩 } \\
\infty \\
\infty \\
0\end{array}$ & $\begin{array}{l}\text { ठ } \\
\infty \\
\approx\end{array}$ & 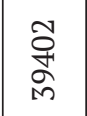 \\
\hline $\begin{array}{c}\text { Среднегодовая численность } \\
\text { занятых, тыс. чел. }\end{array}$ & 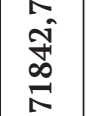 & $\begin{array}{l}\hat{\sigma} \\
\text { ळे } \\
\stackrel{n}{n}\end{array}$ & $\underset{\text { fin }}{\stackrel{0}{n}}$ & $\hat{\tilde{n}}$ & $\begin{array}{l}a \\
\infty \\
\phi_{+}\end{array}$ & $\begin{array}{l}\stackrel{\sim}{A} \\
\vec{F}\end{array}$ & 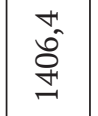 & 悀 & $\stackrel{m}{\mathcal{M}^{2}}$ & $\begin{array}{l}\infty \\
\hat{\sigma}\end{array}$ \\
\hline Численность населения, тыс. чел. & 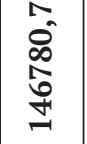 & 胥 & $\underset{\exists}{\rightleftarrows}$ & $\begin{array}{l}\infty \\
\stackrel{n}{q}\end{array}$ & $\underset{\substack{1 \\
\infty \\
\infty}}{1}$ & $\stackrel{\ln }{\stackrel{F}{F}}$ & 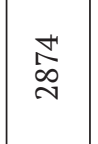 & ڤ̊ & $\hat{\sigma}$ & $\frac{\infty}{\sigma}$ \\
\hline Площадь территории, тыс.км² & $\begin{array}{l}\text { స్ } \\
\text { సี } \\
\text { ה్ }\end{array}$ & $\stackrel{g}{\sharp}$ & के & $\begin{array}{l}\infty \\
\sigma^{-} \\
\stackrel{-}{-}\end{array}$ & $\begin{array}{l}\infty \\
\hat{\sigma}^{-} \\
\not\end{array}$ & $\begin{array}{l}m \\
\stackrel{2}{2}\end{array}$ & $\begin{array}{l}\infty \\
b^{\circ} \\
\stackrel{0}{0} \\
\text { N. }\end{array}$ & $\begin{array}{l}\text { n } \\
\text { D } \\
0 \\
O \\
m\end{array}$ & $\stackrel{\ln }{\stackrel{N}{N}}$ & $\begin{array}{l}\ln _{0} \\
0_{0}^{\infty} \\
-1\end{array}$ \\
\hline 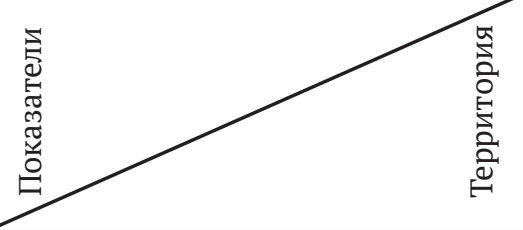 & 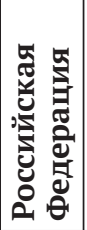 & 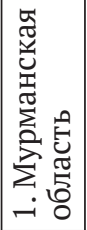 & 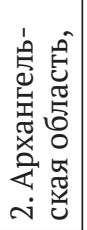 & 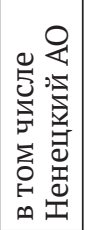 & 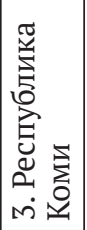 & 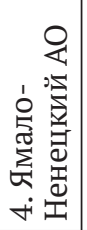 & 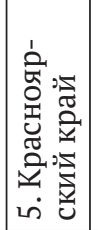 & 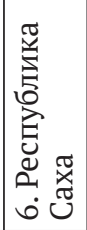 & 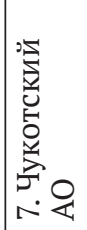 & 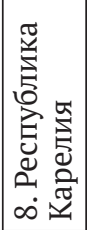 \\
\hline
\end{tabular}


даст более благоприятные условия для жизни и трудовой деятельности как местного населения, включая коренные народы Севера, так и вахтовых работников, способствуя реализации социального аспекта стратегии развития АЗРФ. В-третьих, международные транспортные коридоры, образующие российскую национальную трансарктическую полимагистраль, несут в себе потенциал крупного источника доходов в части предоставления услуг по доставке грузов по более привлекательным для целого ряда государств северным маршрутам [4]. Иными словами, можно отметить, что развитие транспортнологистической инфраструктуры АЗРФ будет сопровождаться значительными мультипликативными эффектами.

Признанной целью реализации крупных инфраструктурных проектов в АЗРФ является создание единой логистической системы, которая должна обеспечивать оптимальное прохождение материальных и информационных потоков с минимальными затратами. Фрагментарный характер существующей на сегодняшний день логистической инфраструктуры российской Арктической зоны, неразвитость береговой инфраструктуры вдоль ключевых арктических маршрутов, очевидная недостаточность имеющихся железнодорожных путей значительно повышают сложность и стоимость работ в рамках имеющихся масштабных проектов [5]. В ряде случаев вполне обоснованным представляется отказ от попыток модернизации имеющейся инфраструктуры и ее проектирование «с нуля» В контексте единого мегапроекта [6].

С учетом стратегической значимости арктических регионов для нашей страны в целом, создание соответствующей транспортнологистической инфраструктуры должно происходить в рамках государственно-частного партнерства как наиболее приемлемой, а, по сути, единственно возможной формы реализации крупномасштабных и сверхзатратных проектов.

С данной точки зрения существенное значение приобретает разработка эффективных региональных инвестиционных стратегий, что ставит вопрос о необходимости повышения инвестиционной привлекательности регионов АЗРФ. Территории, входящие в состав Арктической зоны РФ, обладают неоднородным инвестиционным потенциалом. Объем продукции обрабатывающих отраслей РФ, приходящихся на арктические регионы, составляет не более $2 \%$, причем большая часть этой продукции производится в Ямало-Ненецком АО и в Якутии [7]. В Ямало-Ненецком АО сосредоточены огромные запасы нефти и газа, в том числе на материковом шельфе, на севере Красноярского края традиционно добывают цветные металлы, в Чукотском АО - золото. Ненецкий $\mathrm{AO}$, к примеру, в последние несколько лет характеризуется нулевым уровнем иностранных инвестиций [8]. Определенными преимуществами с точки зрения диверсификации деятельности и степени развития логистической инфраструктуры обладает Мурманская область, начало активного промышленного развития которой относится к первой половине прошлого века. Именно порт Мурманска и вся Кольская опорная зона рассматриваются в качестве ключевого инфраструктурного узла АЗРФ. Таким образом, реализация крупных инфраструктурных проектов в российской Арктике, помимо непосредственно государственных инвестиций, требует привлечения частного капитала, что определяет необходимость создания привлекательных для потенциальных инвесторов условий работы и четких гарантий со стороны региональных и федеральных властей. Дополнительным ограничением в данном случае служит тот факт, что реализация логистических цепочек российских добывающих компаний в Арктике нередко сопряжена с привлечением иностранных партнеров, особенно в части сервисного обслуживания, что делает эти компании весьма чувствительными к существующим и потенциально возможным новым западным санкциям, введенным в отношении многих российских юридических лиц, ведущих свою деятельность в Арктической зоне [9].

Возможности оптимизации логистических затрат экономических субъектов в Арктической зоне Российской Федерации во многом определяются комплексностью развития основных транспортных магистралей, объединяемых в национальную трансарктическую полимагистраль - высокоширотный Северный транспортный коридор, который объединяет в себе Северный морской путь и обслуживающие его речные и железнодорожные подходы. В рамках данного мегапроекта должен быть создан единый логистический комплекс от Мурманска до Петропавловска-Камчатского, включающий различные виды транспорта, соответствующую периферийную инфраструктуру, а также сопут- 
ствующие информационные потоки и учетные системы, призванные обеспечить доставку и перевалку грузов на морские суда и ледоколы.

Комплексность развития транспортнологистической системы АЗРФ предусматривает, в частности, обеспечение арктических портов необходимыми железнодорожными подходами [4]. Важнейшим преимуществом грузоперевозок по железным дорогам являются значительно более короткие, по сравнению с судамиконтейнеровозами, сроки доставки, однако стоимость перевозки железнодорожным транспортом выше.

Среди ключевых проектов по созданию транспортно-логистической инфраструктуры в материковой части АЗРФ, призванной обеспечить пространственную связанность страны, входят такие проекты как строительство в Ямало-Ненецком АО железнодорожной магистрали Обская - Салехард - Надым - Новый Уренгой - Коротчаево («Северный широтный ход»), призванной соединить месторождения полезных ископаемых в Арктике с промышленным центром Уральского федерального округа; продолжением «Северного широтного хода» должен стать проект по строительству железной дороги «Бованенково - Сабетта», который позволит оптимизировать доставку грузов в соответствующий порт на Ямале. В настоящее время реализуется проект Мурманского транспортного узла, предусматривающий создание на берегу Кольского залива нефтяного и угольного терминалов, а также строительство железной дороги Выходной - Лавна. Запланированы к реализации проекты железнодорожных магистралей «Белое море - Коми - Урал» - «Белкомур» (должна соединить Пермский край, Республику Коми и Архангельскую область), «Баренцево море - Коми - Урал» - «Баренцкомур» (должна соединить Индигу, Сосногорск, Полуночное и Сургут) и др. [10]. Таким образом, строительство новых железных дорог к портам Баренцева, Белого, Карского морей, моря Лаптевых как части единого транспортно-логистического комплекса АЗРФ способствует потенциальному увеличению грузопотоков, проходящих через северные морские порты России, и, что чрезвычайно важно, повышает конкурентоспособность Северного морского пути путем сокращения времени доставки грузов: если доставка грузов в Европу морским путем через Суэцкий канал составляет около 30 суток, то при условии реализации указанных железнодорожных проектов срок доставки по Северному морскому пути может быть сокращен до 18-22 суток [11].

Ключевым проектом в части создания транспортно-логистической инфраструктуры российской Арктики, что подчеркивается во всех без исключения программных документах, в т.ч. в Указе Президента РФ «Об Основах государственной политики Российской Федерации в Арктике на период до 2035 года» и «Стратегии развития Арктической зоны Российской Федерации и обеспечения национальной безопасности на период до 2020 года», остается развитие Северного морского пути - географически кратчайшего маршрута, соединяющего Европейские регионы и Дальний Восток. Основными целями проектов развития этого арктического маршрута является расширение пропускной способности Северного морского пути, укрепление национальной безопасности РФ в Арктике, а также оптимизация логистических затрат с целью увеличения коммерческой привлекательности использования этой арктической магистрали. Значительный коммерческий потенциал Северного морского пути заключается не только в создании условий для более широкого освоения ресурсов российской Арктики или сокращении времени доставки товаров российского экспорта, но и возможности использования этой магистрали в целях международного коммерческого транзита.

Существенным ограничением, которое в настоящий момент значительно снижает возможности использования Северного морского пути в указанных направлениях, является неукомплектованность отечественного ледокольного флота, способного осуществлять проводку судов арктическими маршрутами. Именно современный ледокольный флот обеспечивает своевременную доставку грузов для населения труднодоступных северных районов, обеспечивает снабжение добывающих компаний, работающих в Арктике, а также объектов военного назначения и группировки российских войск в Арктике [12]. Первостепенной представляется задача пополнения российского линейного ледокольного флота, в т.ч. за счет современных атомных ледоколов.

Особое значение в развитии Северного морского пути, а также развитии российского экспорта сжиженного газа как альтернативы традиционным газопроводам, приобретает газовозный флот ледокольного класса. Существу- 
ющих мощностей по круглогодичному вывозу сжиженного газа явно недостаточно (работают только пять газовозов ледокольного класса) [13]. Возможным решением по высвобождению части ледокольных газовозов, предлагаемым рядом экспертов, может стать создание в районе Мурманска береговых газохранилищ для перегрузки газа с газовозов ледокольного класса на простые газовозы, что увеличит сроки доставки, но позволит более широко задействовать имеющиеся ледокольные газовозы в Арктике в ожидании завершения строительства новых [13]. Расширение отечественного ледокольного флота создаст условия для предоставления российских судов ледокольного типа в аренду и оказание услуг по проводке судов по Северному морскому пути, что потенциально может стать одной из ключевых статей российского экспорта в Арктике.

Таким образом, вопрос развития и повышения конкурентоспособности Северного морского пути как российской трансарктической полимагистрали непосредственно зависит от развития соответствующей транспортно-логистической инфраструктуры, что подразумевает модернизацию имеющихся и строительство новых портов и морских транспортных терминалов, пополнение отечественного ледокольного флота и строительство транспортных судов, создание специализированного геологоразведывательного флота и создания инфраструктуры для обслуживания добычи полезных ископаемых на морском шельфе [4]. Следует, однако, отметить, что арктическая логистика в масштабах Российской Федерации не ограничивается только Северным морским путем, который, в строгом понимании, представляет собой водную магистраль от Карских ворот на западе до Берингова пролива на востоке. Оптимизация логистических затрат в АЗРФ требует развития навигационногидрографического обеспечения всего судоходства в Арктике, что будет способствовать расширению как коммерческого гражданского судоходства, так и окажет существенное содействие укреплению российского ВМФ в регионе.

Развитие Северного морского пути не может полноценно реализовываться без решения задачи по созданию современной системы авиационного обслуживания арктических районов. Основой создания подобной системы представляется модернизация имеющейся сети аэропортов АЗРФ, не смотря на ее значительное сокращение в последние десятилетия, а также развитие малой авиации. Перспективным представляется также развитие маршрутов кроссполярных сообщений, способных обеспечить существенную экономию затрат при транспортировке грузов между Евразией и Северной Америкой с возможностью запуска в перспективе и пассажирских перевозок [4].

Развитие авиационного транспорта будет содействовать решению проблемы обеспечения регионов АЗРФ трудовыми ресурсами посредством формирования эффективной транспортно-логистической модели доставки сотрудников к географически удаленным объектам российской Арктики. Реализация цели поддержания достойного качества жизни населения, проживающего в АЗРФ, указанной в Основах государственной политики Российской Федерации в Арктике до 2035 года, также представляется весьма затруднительной без повышения доступности авиационного транспорта для населения российского Заполярья.

Экономический потенциал, которыми обладают регионы АЗРФ, способен стать точкой роста для всей экономики России, однако возможности его реализации во многом зависят от скоординированности действий федеральной и местной властей, частных инвесторов и прочих групп стейкхолдеров. По мнению экспертов Российская Федерация обладает возможностями по преобразованию Северного морского пути в некий аналог Суэцкого канала как международной транзитной магистрали с предоставлением возмездного доступа к нему всем заинтересованным лицам, однако подобный проект требует не только привлечения колоссальных финансовых ресурсов, но и серьезной проработки в части международного права в связи с ростом внимания ряда государств к арктическим территориям в последние годы [13].

Таким образом, для успешной реализации масштабных арктических проектов, в т.ч. создания в регионе в среднесрочной перспективе современной транспортно-логистической инфраструктуры, обеспечивающей оптимизацию логистических затрат, требуется объединение усилий государства, крупного бизнеса, которые заинтересованы в создании условий для разработки богатейших месторождений природных ресурсов, а также среднего и малого бизнеса, получающих мощный стимул к развитию только с появлением в регионе современной инфра- 
структуры по обслуживаю городов и населенных пунктов, что, в свою очередь, обеспечит повышение качества жизни местного населения [13].

Еще одним принципиально важным вектором развития логистической инфраструктуры российской Арктики должно стать изначальное согласование процесса проектирования с целями устойчивого развития уникального региона [14]. Совокупность факторов природноклиматического, экологического и социального характера, таких как чрезвычайно суровые природные условия, потенциально разрушительные последствия глобального потепления, крайняя малонаселенность и уникальность жизненного уклада коренных малочисленных народов Севера требует исключительно ответственного подхода к проектированию и созданию объектов транспортно-логистической инфраструктуры в АЗРФ. С другой стороны, как уже было отмечено, арктическая логистическая инфраструктура может выступать в качестве стимулирующего фактора социального развития региона, обеспечивая возможность комфортного перемещения местного населения и работников к удаленным объектам, стимулируя появление объектов малого и среднего предпринимательства в регионе и пр., что полностью соответствует глобальной цели «Индустриализация, инновации и инфраструктура» в области устойчивого развития $\mathrm{OOH}$.
Другим примером необходимости учета факторов устойчивого развития при создании транспортно-логистической инфраструктуры в Арктике и планировании логистических затрат может служить тот факт, что одним из последствий глобального потепления может стать увеличение проходимости Северного морского пути в связи с таянием арктических льдов, что приведет к сокращению времени доставки грузов по нему, корректировке состава ледокольного флота РФ, и, как следствие, общему изменению международных торговых маршрутов в Арктике.

Таким образом, Российская Федерация, выступая в роли евразийского морского государства, обладает уникальными предпосылками для использования экономического потенциала своих арктических регионов в части оптимизации логистических затрат и диверсификации источников доходов в случае участия в международных арктических проектах, однако только сбалансированное развитие промышленнопроизводственного потенциала региона при широкой государственной поддержке в совокупности с учетом ключевых рисков социальноэкономического и природно-экологического характера создаст необходимую базу для оптимизации логистических затрат в Арктической зоне Российской Федерации.

\section{Библиографический список}

1. Указ Президента Российской Федерации от 05.03.2020 г. № 164 «Об Основах государственной политики Российской Федерации в Арктике на период до 2035 года». URL: http://publication.pravo.gov.ru/Document/Vi ew/0001202003050019?index=2 \&rangeSize=1 Дата обращения: 06.03.2020.

2. Алексеева М.Б.Системная диагностика стратегии развития промышленности Арктики / М.Б.Алексеева, В.Ф.Богачев, М.А. Горенбургов // Записки Горного института. 2019. Т. 238. С. 450-458. DOI 10.31897/ PMI.2019.4.450.

3. Хайкин М.М. Организационно-экономические аспекты развития механизмов рационального использования угольных месторождений. М. М. Хайкин, У. Чимэддорж // Евразийский юридический журнал. 2018 . № 5 (120). С. 352-354.

4. Фадеев А. Транспортно-логистические задачи в Арктике и перспективы международного сотрудничества. URL: http://pro-arctic.ru/04/04/2014/resources/7533 Дата обращения: 03.05.2020.

5. Vilkina M.V., Klimovets O. V. Augmented reality as marketing strategy in the global competition. Lecture Notes in Networks and Systems. 2020. V. 91. Р. 54-60.

6. Черенков В.И., Климовец О.В., Таничев А. В. Логистическая инфраструктура: от формирования понятия к построению исследовательской модели освоения Арктики // Фундаментальные исследования. 2020. №3, С. 142-151.

7. Алексеева М.Б.Системная диагностика стратегии развития промышленности Арктики / М.Б.Алексеева, В.Ф.Богачев, М.А. Горенбургов // Записки Горного института. 2019. Т. 238. С. 450-458. DOI 10.31897/ PMI.2019.4.450.

8. Регионы России. Социально-экономические показатели - Федеральная служба государственной статистики. Официальное издание. 2019. URL: https://www.gks.ru/storage/mediabank/Region_Pokaz_2019.pdf Дата обращения: 24.02.2020. 
9. Веретенников Н.П. Формирование и развитие логистической инфраструктуры в регионах Арктики // Север и рынок: формирование экономического порядка. 2019. № 1 (63). С. 89-98. DOI 10.25702/KSC.2220802Х.1.2019.63.89-98.

10. Орлов Д. Развитие Арктической зоны России и основные вызовы для ее освоения // Информационное агентство REGNUM. 25.04.2018. URL: https://regnum.ru/news/economy/2407690.html Дата обращения: 22.02.2020.

11. Леонтьев Р.Г., Орлов А. Л. Транзитный потенциал транспорта Дальнего Востока Российской Федерации (гипотезы и реалии) / М-во трансп. РФ, Федер. агентство ж.-д. трансп., Дальневосточный гос. ун-т путей сообщ., Рос. акад. наук, Дальневосточное отделение ВЦ ДВО РАН. Хабаровск, 2011. С. 467.

12. Богачев В. Ф., Веретенников Н. П., Евграфова Л. Е. Социально-экономические аспекты устойчивого развития промышленного рыболовства в Арктике // Вестник МГТУ. 2014. Т. 17, № 3. С. 431-436.

13. Веретенников Н.П. Формирование и развитие логистической инфраструктуры в регионах Арктики // Север и рынок: формирование экономического порядка. 2019. № 1 (63). C. 89-98. DOI 10.25702/KSC.2220802Х.1.2019.63.89-98.

14. Васильев Ю.С., Диденко Н.И., Черенков В.И. Некоторые проблемы и перспективные драйверы устойчивого развития Арктической зоны Российской Федерации // Север и рынок: формирование экономического порядка. 2019. № 1 (63). С. 4-26. 